\title{
A High-Performance Liquid Chromatography:Chemiluminescence Method for Potential Determination of Vardenafil in Dietary Supplement
}

\author{
Youjun Di, ${ }^{1}$ Min Zhao, ${ }^{2}$ Yingchun Nie, ${ }^{1}$ Fei Wang, ${ }^{3}$ and Jiagen $\mathrm{Lv}^{2}$ \\ ${ }^{1}$ Department of Chemistry, Shaanxi Institute of Education, Xi'an 710061, China \\ ${ }^{2}$ School of Chemistry and Material Science, Shaanxi Normal University, Xi'an 710062, China \\ ${ }^{3}$ The Vice Squad; Xi'an Municipal Public Security Bureau Yanta, Xi'an 710061, China
}

Correspondence should be addressed to Youjun Di, sjydiyj@163.com

Received 6 October 2010; Accepted 26 November 2010

Academic Editor: Jianxiu Du

Copyright () 2011 Youjun Di et al. This is an open access article distributed under the Creative Commons Attribution License, which permits unrestricted use, distribution, and reproduction in any medium, provided the original work is properly cited.

\begin{abstract}
A flow method of high-performance liquid chromatography (HPLC) seperation and chemiluminescence (CL) detection for sensitive vardenafil analysis in dietary supplements was developed. The vardenafil separation was achieved on a C18 column at $30^{\circ} \mathrm{C}$ using ethanol- $\mathrm{H}_{3} \mathrm{PO}_{4}$ and ethylenediaminetetraacetic acid disodium salt $\left(\mathrm{Na}_{2} \mathrm{EDTA}\right)$ aqueous solution $(25: 75, \mathrm{v} / \mathrm{v} \%)$ as mobile phase. The followed continuous CL detection was conducted based on the strong CL enhancement by the presence of vardenafil to luminol- $\mathrm{K}_{3} \mathrm{Fe}(\mathrm{CN})_{6}$ reaction in alkaline medium. At the flow rate of $0.8 \mathrm{~mL} / \mathrm{min}$, the vardenafil retention time $\left(t_{R}\right)$ was $6.4 \mathrm{~min}$. Factors that affected the HPLC resolution and CL detection were studied and optimized. The calibration curve obtained for vardenafil standard was linear in concentration range of $8.0 \times 10^{-7} \sim 1.0 \times 10^{-4} \mathrm{~mol} / \mathrm{L}$. The relative standard deviations (RSD) of intraday and interday precision were less than $3.5 \%$. The proposed method was applied to the vardenafil determination in oral liquid, wine, and capsule samples.
\end{abstract}

\section{Introduction}

A dietary supplement is a product, which contains a "dietary ingredient" intended to supplement the diet. In general, the natural dietary supplements for male sexual potency consist of different herbal extracts such as ginseng root, lychee seed, barbary wolfberry fruit, longan aril, and aweto. These dietary supplements could improve male sexual potency without causing danger, even when overdose occurred [1]. Recently, chemically synthetic phosphodiesterase-5 (PDE-5) inhibitors have been used to improve erectile dysfunction (ED), one of the most popularly used is vardenafil hydrochloride (Levitra), 2-[2-ethoxy-5-(4-ethyl-piperazine-1-sulfonyl)phenyl]-5-methyl-7-propyl-3H-imidazo[5,1-f]-[1,2,4]triazin-4-one monohydrochloride, trihydrate (Figure 1). Vardenafil, approved by the United States Food and Drug Administration (FDA) in 2003, is a new oral, potent, highly selective phosphodiesterase-5 (PDE5) inhibitor marketed for the improvement of ED in man [2]. Studies have shown that doses of vardenafil $(10-40 \mathrm{mg})$ are rapidly absorbed following oral administration, reaching maximum plasma concentration in some men within 15 minutes [3]. Nevertheless, it has been proved that vardenafil poses a serious health risk [4], such as headache [5], low blood pressure [6], flushing, dyspepsia, and nasal congestion or rhinitis [7]. Thus, vardenafil could be legally obtained only with a doctor's prescription. However, some illegal dealers add vardenafil into dietary supplement products for the sake of profit. For purposes of quality control and health safety, establishing sensitive and selective methods to detect illegal vardenafil addition in dietary supplements are necessary.

As shown in the literatures, several methods have been reported for vardenafil determination in dietary supplements such as LC-MS and GC-MS method [8], LC-ESIMS method [1, 4], LC-ESI-MS/MS method [9], MRM-ESIMS-MS method [10], and FTICRMS method [11]. It is noticed that all these methods are developed based on the MS detection. MS provides sensitive and reliable results, but 


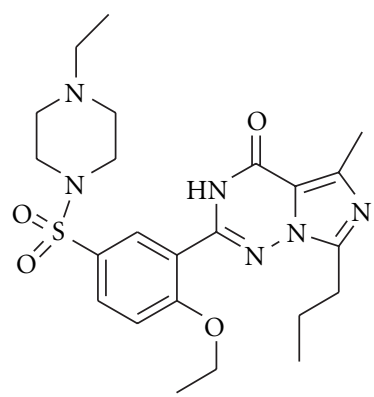

FIGURE 1: Structure of vardenafil.

it also implies highly sophisticated apparatus, careful control of conditions and relatively high operation cost. What is more, MS is inaccessible in most laboratories. Thus, simpler, automated and less expensive methods are still necessary.

Taking the advantages of perfect versatility and easy fluidic manipulation, flow injection (FI) has achieved great success in the development for automated analysis. The integration of FI and high-performance liquid chromatography (HPLC) has also showed the power for the complex samples analysis. Chemiluminescence (CL) detection is a highly sensitive analytical technique. CL-based technique as a means of detection for HPLC aroused the analysts interest in recent years $[12,13]$, although CL detection is not as universal as fluorescence detection or ultraviolet visible detection, it is more selective for fewer interfering species observed in the chromatogram [14] and sensitive for a large $\mathrm{CL}$ signal-to-noise ratio $(\mathrm{S} / \mathrm{N})$ and wide linear working range [12]. The combination of HPLC high resolution, CL sensitive detection and FI manipulation would be one of the plausible techniques for a sensitive, precise, and facile determination of trace levels of compounds in the complex mixture of substances [13]. Recent studies witness rapid progress in HPLC-CL method, which is widely used to perform diverse qualitative and quantitative analytical problems [15-18].

Our experiments indicated that in alkaline medium the $\mathrm{CL}$ of luminal $-\mathrm{K}_{3} \mathrm{Fe}(\mathrm{CN})_{6}$ could be greatly enhanced by the presence of trace vardenafil. Based on above phenomenon, an automated HPLC-CL method for vardenafil determination in dietary supplements was developed. Various experiments were conducted to establish the optimum analytical conditions. The proposed method exhibited the advantages of automated operation, high analytical throughput, simple instrumentation, wide linear range, and reagent-saving and was applied to oral liquid, wine, and capsule samples analysis.

\section{Experimental}

2.1. Reagents and Chemicals. Ethanol and methanol were of HPLC grade. All the other reagents were of analytical reagent grade unless specified otherwise, and deionized and doubly distilled water was used throughout. Vardenafil hydrochloride trihydrate (purity, 99.6\%) was purchased from Qiyu Biology Co., Ltd. (Xi'an, China). Luminol was obtained from Kangpei Technology Company (Xi'an, China). Other reagents including $\mathrm{K}_{3} \mathrm{Fe}(\mathrm{CN})_{6}, \mathrm{H}_{3} \mathrm{PO}_{4}$, ethylenediaminetetraacetic acid disodium salt $\left(\mathrm{Na}_{2} \mathrm{EDTA}\right)$, and $\mathrm{NaOH}$ were supplied by Xi' an Chemical Reagent Factory (Xi'an, China).

Vardenafil stock solution $\left(5.0 \times 10^{-3} \mathrm{~mol} / \mathrm{L}\right)$ was prepared by ethanol and stored at $-20^{\circ} \mathrm{C}$ in a refrigerator. Standard series from $8.0 \times 10^{-7} \sim 1.0 \times 10^{-4} \mathrm{~mol} / \mathrm{L}$ were prepared daily by sequentially diluting stock solution with mobile phase solution. A $1.0 \times 10^{-2} \mathrm{~mol} / \mathrm{L} \mathrm{K} \mathrm{K}_{3} \mathrm{Fe}(\mathrm{CN})_{6}$ stock solution was prepared by dissolving $164.6 \mathrm{mg}$ of $\mathrm{K}_{3} \mathrm{Fe}(\mathrm{CN})_{6}$ in $50 \mathrm{~mL}$ water, and it was protected against light and stored at $4^{\circ} \mathrm{C}$ in a refrigerator. A $1.0 \times 10^{-2} \mathrm{~mol} / \mathrm{L}$ stock solution of luminol was prepared in $0.1 \mathrm{~mol} / \mathrm{L} \mathrm{NaOH}$ solution. Furthermore, these stock solutions were reprepared each one month.

The mobile phase consisting of ethanol and an aqueous solution containing $1.0 \times 10^{-2} \mathrm{~mol} / \mathrm{L} \mathrm{H}_{3} \mathrm{PO}_{4}$ and $2.0 \times$ $10^{-4} \mathrm{~mol} / \mathrm{L} \mathrm{Na}_{2}$ EDTA $(25: 75, \mathrm{v} / \mathrm{v} \%)$ was prepared. Mobile phase was filtered through $0.45 \mu \mathrm{m}$ Millipore membrane of polytetrafluoroethylene (PTFE) and further degassed in an ultrasonic bath before use.

2.2. Sample Preparation. Health food samples including one herbal oral liquid, one herbal medicated wine, and one herbal capsule claimed being capable of enhancing sexual performance for men that were under suspicion of adulteration, were purchased from local drug store and market. A portion of oral liquid and wine sample were, respectively, 10-fold diluted with mobile phase solution, filtered through a $0.45 \mu \mathrm{m}$ PTFE membrane filter (Shanghai Xinya Purifier Devices Factory, Shanghai, China) and finally degassed prior to use. For capsule sample preparation, three capsule contents were emptied and mixed sufficiently. One capsule weight powder was transferred to a $50 \mathrm{~mL}$ beaker, and vortically extracted with $10 \mathrm{~mL}$ mobile phase solution for $1 \mathrm{~h}$. A portion of the extraction solution was filtered through a $0.45 \mu \mathrm{m}$ PTFE membrane filter and diluted with mobile phase solution for further analysis.

2.3. Apparatus and Procedures. As illustrated in Figure 2, the HPLC-CL experimental setup consisted of a CL analyzer (Xi'an Remex Analyse Instrument Co., Ltd, Xi'an, China) equipped with a Hamamatsu R456 PMT (Tokyo, Japan) and a negative high voltage (NHV) generator, a planar coiled transparent PTFE flow cell, a $1.8 \mathrm{~mL} / \mathrm{min}$ constant flow rate CL pump (Shanghai Instrument Electric Motor Factory, Shanghai, China), a LC-10AT liquid chromatography (Shimadzu, Tokyo, Japan) equipped with a Rheodyne $7725 \mathrm{i}$ syringe-loading sample valve $(20 \mu \mathrm{L}-\mathrm{loop}$, Cotati, CA, USA), a Waters C18 column (i.d.: $4.6 \mathrm{~mm} \times 150 \mathrm{~mm}$, particle size: $5 \mu \mathrm{m}$, USA) and a DT-230A column oven (Tianjin DoChrom Technology Co., Ltd, Tianjin, China). The mobile phase flow rate was set at $0.8 \mathrm{~mL} / \mathrm{min}$. The $\mathrm{C} 18$ column temperature was controlled at $30^{\circ} \mathrm{C}$.

Using the described experimental setup, HPLC pump and CL pump were started. Stream a containing $1.0 \times$ $10^{-5} \mathrm{~mol} / \mathrm{L}$ luminol, $2.0 \times 10^{-4} \mathrm{~mol} / \mathrm{L} \mathrm{Na}_{2} \mathrm{EDTA}$, and $1.0 \mathrm{~mol} / \mathrm{L} \mathrm{NaOH}$ and stream b containing $1.0 \times 10^{-5} \mathrm{~mol} / \mathrm{L}$ $\mathrm{K}_{3} \mathrm{Fe}(\mathrm{CN})_{6}$ delivered by CL pump merged in the T1. Then, 


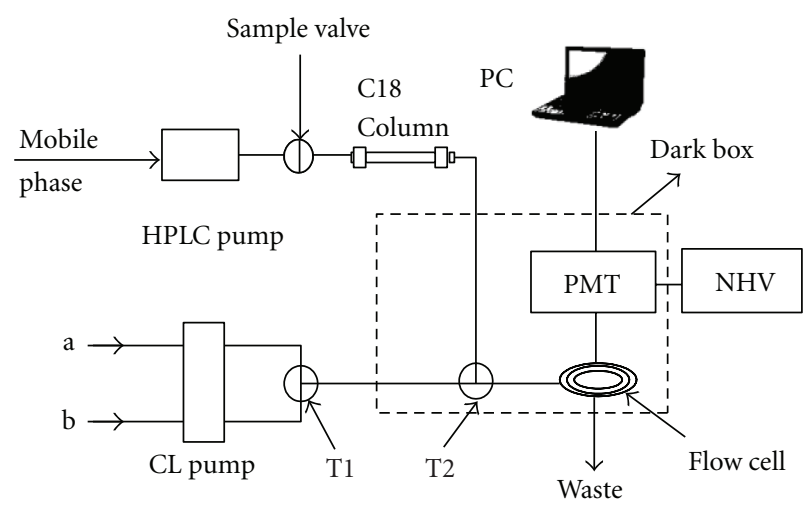

Figure 2: Schematic diagram of the proposed HPLC-CL integration for vardenafil analysis. a: luminol $+\mathrm{Na}_{2} \mathrm{EDTA}+\mathrm{NaOH}$; b: $\mathrm{K}_{3} \mathrm{Fe}(\mathrm{CN})_{6}$; PMT: photomultiplier tube; $\mathrm{NHV}$ : negative high voltage generator $(-400 \mathrm{~V})$; PC: computer; T1 and T2: three-way mixer 1 and 2 .

the reagent mixture merged with mobile phase in the T2 and generated a stable CL baseline. Subsequently, when the sample valve was switched to the injection position, $20 \mu \mathrm{L}$ standard or sample was injected into the mobile phase. Outflow vardenafil reacted with the reagent mixture and generated the enhanced CL signal in the flow cell. The CL signal was recorded as a function of time and CL intensity by the Remex Analyzer with the PMT operated at $-400 \mathrm{~V}$. A microcomputer equipped with Remex Software running under Windows XP was employed for data treatment. Vardenafil peak identification was carried out by the standard addition method and the retention time $\left(t_{R}\right)$ of vardenafil. The peak height, $\Delta I\left(\Delta I=I_{S}-I_{0}\right.$, where $I_{0}$ was the CL of baseline, $I_{S}$ was the peak CL of vardenafil) was used to quantify vardenafil content by means of the related calibration equation.

\section{Results and Discussion}

3.1. CL Reaction Selection. For vardenafil CL determination, we considered several known CL reactions including alkaline luminol- $\mathrm{H}_{2} \mathrm{O}_{2}$, alkaline luminol- $\mathrm{K}_{3} \mathrm{Fe}(\mathrm{CN})_{6}$, alkaline luminol- $\mathrm{KIO}_{4}$, acidic $\mathrm{KMnO}_{4}$, acidic $\mathrm{KMnO}_{4}-\mathrm{HCHO}$, acidic $\mathrm{KMnO}_{4}-\mathrm{Na}_{2} \mathrm{SO}_{4}$, and $\mathrm{NaClO}-\mathrm{NaOH}$. To prevent the possible interference from metal ions, $2.0 \times 10^{-4} \mathrm{~mol} / \mathrm{L} \mathrm{Na}{ }_{2}$ EDTA was used in all luminol concerned reactions. Experimental results indicated that alkaline luminol- $\mathrm{K}_{3} \mathrm{Fe}(\mathrm{CN})_{6}$ reaction contributed the strongest CL response to $1.0 \times 10^{-5} \mathrm{~mol} / \mathrm{L}$ vardenafil presence. Therefore, alkaline luminol- $\mathrm{K}_{3} \mathrm{Fe}(\mathrm{CN})_{6}$ CL reaction was selected for subsequent investigations.

3.2. Kinetic Curve. The kinetic curve of the alkaline luminol$\mathrm{K}_{3} \mathrm{Fe}(\mathrm{CN})_{6}$-vardenafil CL reaction was studied with a static injection method. Alkaline luminal and $\mathrm{K}_{3} \mathrm{Fe}(\mathrm{CN})_{6}$ solution were mixed in the beaker placed in front of the PMT window. After a stable baseline was obtained, $1.0 \mathrm{~mL} 1.0 \times$ $10^{-4} \mathrm{~mol} / \mathrm{L}$ vardenafil standard was injected into the beaker by a syringe. The kinetic curve recorded as a function of time and CL intensity, and it could be concluded that vardenafil greatly enhanced luminol- $\mathrm{K}_{3} \mathrm{Fe}(\mathrm{CN})_{6} \mathrm{CL}$, which reached a maximum within $1.5 \mathrm{~s}$. Thus, the studied CL reaction was a fast reaction. As a result, the T2 was placed as near as possible to the flow cell inside the dark box as shown in Figure 2.

3.3. Optimization of HPLC-CL System. To obtain the sensitive and fast vardenafil detection with the described HPLCCL system, a series of experiments were conducted to establish optimum analytical performance. $1.0 \times 10^{-5} \mathrm{~mol} / \mathrm{L}$ vardenafil standard was used in all optimization experiments. Both mobile phase and luminol solution contained $2.0 \times$ $10^{-4} \mathrm{~mol} / \mathrm{L} \mathrm{Na} \mathrm{NaDTA}_{2}$. Luminol and $\mathrm{K}_{3} \mathrm{Fe}(\mathrm{CN})_{6}$ flow rates were controlled at $1.8 \mathrm{~mL} / \mathrm{min}$, respectively. Experimental optimum analytical performances were selected based on the biggest CL S/N values and on the average of three injections for each test when the relative standard deviation (RSD) of each test point was less than 5.0\%, unless specified otherwise.

3.4. HPLC Optimization. For HPLC-CL analysis, the mobile phase should be, not only suitable for vardenafil separation in complex matrix but also compatible with CL detection. Acetonitrile-acidic aqueous buffer $[1,4,11,19]$ and methanol-acidic aqueous buffer $[8,20]$ were the most commonly used mobile phases for vardenafil separations on C18 column. When investigating the compatibility of acetonitrile with CL detection, it was found that acetonitrile brought about very high CL background. This high background went against the sensitive vardenafil detection. Similar experiments showed that when methanol and ethanol were used, relatively low CL backgrounds and smooth baselines could be obtained. Thus, methanol and ethanol were selected to constitute the mobile phases for the posterior study.

The effect of organic phase volume percentage $(\mathrm{v} / \mathrm{v} \%$, organic phase volume/organic + aqueous phase volume) on $t_{R}, \mathrm{~S} / \mathrm{N}$ value and column pressure $(P)$, were investigated in the range of $40 \%-60 \%$ methanol and $20 \%-30 \%$ ethanol, respectively. Observing the experimental results listed in Table 1, it could be concluded that the higher the $\mathrm{v} / \mathrm{v} \%$, the shorter the $t_{R}$, and $30 \%$ ethanol contributed the biggest $\mathrm{S} / \mathrm{N}$ value. However, $30 \%$ ethanol also caused relatively high $P$. Thereupon, as a compromise among the bigger $\mathrm{S} / \mathrm{N}$ value, shorter $t_{R}$ and suitable $P, 25 \%$ ethanol was chosen in subsequent experiments.

A number of organic or inorganic acids were employed to constitute mobile phase to improve vardenafil separation $[1,4,8,11,19,20]$. It was known that the selected CL reaction was an oxidative-reductive reaction. Considering the possible reaction between organic acid and CL reagents, inorganic acid was considered to be more suitable for CL detection. Experiment indicated that $\mathrm{H}_{3} \mathrm{PO}_{4}$ could effectively suppress the peak-tailing, and a relatively narrow and symmetric chromatographic peak could be achieved (Figure 3). What is more, as expected, the $t_{R}$ was shortened. With respect to obtaining the biggest $\mathrm{CL} \mathrm{S} / \mathrm{N}$ value, the optimum $\mathrm{H}_{3} \mathrm{PO}_{4}$ concentration was investigated by varying its concentration in the range of $1.0 \times 10^{-4} \sim 1.0 \times 10^{-2} \mathrm{~mol} / \mathrm{L}$. Experiments showed that $\mathrm{S} / \mathrm{N}$ value increased with $\mathrm{H}_{3} \mathrm{PO}_{4}$ concentration increasing. When $\mathrm{H}_{3} \mathrm{PO}_{4}$ concentration was 
TABLE 1: The effect of $\mathrm{v} / \mathrm{v} \%$ of methanol and ethanol on $t_{R}, \mathrm{~S} / \mathrm{N}$ and $P$.

\begin{tabular}{lcccccccc}
\hline $\mathrm{v} / \mathrm{v} \%$ & $20^{\mathrm{a}}$ & $25^{\mathrm{a}}$ & $30^{\mathrm{a}}$ & $40^{\mathrm{b}}$ & $45^{\mathrm{b}}$ & $50^{\mathrm{b}}$ & $55^{\mathrm{b}}$ & $60^{\mathrm{b}}$ \\
\hline$t_{R}(\min )$ & 13.2 & 6.4 & 3.8 & 10.0 & 5.4 & 3.1 & 2.8 & 2.1 \\
$\mathrm{~S} / \mathrm{N}$ & 7.1 & 8.3 & 10.0 & 3.1 & 6.1 & 5.2 & 4.9 & 3.9 \\
$P(\mathrm{Mpa})$ & 9.8 & 12.3 & 16.1 & 10.8 & 11.1 & 10.3 & 10.0 \\
\hline
\end{tabular}

${ }^{a}$ Ethanol

${ }^{\mathrm{b}}$ Methanol

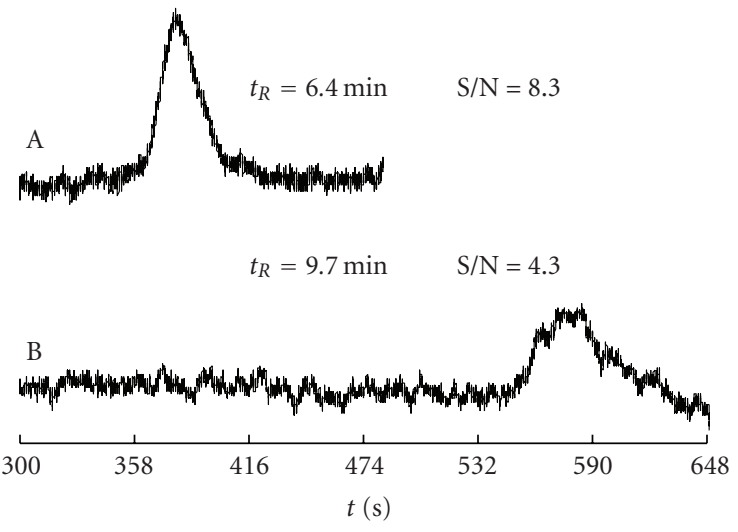

Figure 3: Vardenafil chromatograms with (A) and without (B) $\mathrm{H}_{3} \mathrm{PO}_{4}$ in mobile phase. Mobile phase contained $25 \%$ ethanol and $2.0 \times 10^{-4} \mathrm{~mol} / \mathrm{L} \mathrm{Na} \mathrm{NaDTA}_{2}$.

TABLE 2: The effect of mobile phase flow rate on $t_{R}, \mathrm{~S} / \mathrm{N}$ and $P$.

\begin{tabular}{lccccc}
\hline flow rate $(\mathrm{mL} / \mathrm{min})$ & 0.3 & 0.5 & 0.7 & 0.8 & 0.9 \\
\hline$t_{R}(\min )$ & 17.2 & 10.4 & 7.4 & 6.4 & 5.8 \\
$\mathrm{~S} / \mathrm{N}$ & 5.0 & 6.1 & 7.0 & 8.3 & 5.6 \\
$P(\mathrm{Mpa})$ & 4.2 & 7.3 & 10.0 & 12.3 & 13.8 \\
\hline
\end{tabular}

$1.0 \times 10^{-2} \mathrm{~mol} / \mathrm{L}$, the $\mathrm{pH}$ of mobile phase was about 2.0 , the biggest $\mathrm{S} / \mathrm{N}$ value was obtained. According to the column supplier's suggestion, $\mathrm{H}_{3} \mathrm{PO}_{4}$ concentration higher than $1.0 \times 10^{-2} \mathrm{~mol} / \mathrm{L}$ was not tested. As a result, $1.0 \times 10^{-2} \mathrm{~mol} / \mathrm{L}$ $\mathrm{H}_{3} \mathrm{PO}_{4}$ concentration was employed as the optimum.

As could be seen the experimental results summarized in Table 2, by varying the flow rate from 0.3 to $0.9 \mathrm{~mL} / \mathrm{min}$, the effect of mobile phase flow rate upon CL detection was investigated. It was found that the higher the mobile phase flow rate, the shorter the $t_{R}$ and the higher the $P$. Lastly, a flow rate of $0.8 \mathrm{~mL} / \mathrm{min}$ was chosen as a compromise between the biggest $\mathrm{S} / \mathrm{N}$ value and relatively shorter $t_{R}$.

3.5. CL Optimization. As was well known, the alkaline medium was necessary for luminal- $\mathrm{K}_{3} \mathrm{Fe}(\mathrm{CN})_{6}$ reaction. In our experiments, $\mathrm{NaOH}$ was selected to constitute the alkaline reaction medium. The effect of $\mathrm{NaOH}$ concentration on the CL detection was examined in the range of $0.2 \sim$ $1.3 \mathrm{~mol} / \mathrm{L}$. Experiments showed that the $\mathrm{S} / \mathrm{N}$ value increased with the $\mathrm{NaOH}$ concentration increasing, and a leveling off could be found when the $\mathrm{NaOH}$ concentration was higher than $1.0 \mathrm{~mol} / \mathrm{L}$. Sequent experiments were performed using $1.0 \mathrm{~mol} / \mathrm{L} \mathrm{NaOH}$.
Table 3: Oral liquid, wine, and capsule vardenafil analysis and recovery tests results.

\begin{tabular}{lccccc}
\hline $\begin{array}{l}\text { Sample } \\
\text { Lot No. }\end{array}$ & \multirow{2}{*}{$\begin{array}{l}\text { Vardenafil } \\
\end{array}$} & $\begin{array}{c}\text { Added } \\
10^{-5} \mathrm{~mol} / \mathrm{L}\end{array}$ & $\begin{array}{c}\text { Found } \\
10^{-5} \mathrm{~mol} / \mathrm{L}\end{array}$ & $\begin{array}{c}\mathrm{RSD}^{\mathrm{c}} \\
\%\end{array}$ & $\begin{array}{c}\text { Recovery }^{\mathrm{c}} \\
\%\end{array}$ \\
\hline \multirow{2}{*}{$\begin{array}{l}\text { Oral liquid } \\
22070818\end{array}$} & \multirow{2}{*}{$\mathrm{ND}^{\mathrm{a}}$} & 3.0 & 1.93 & 2.2 & 96.5 \\
& & 4.0 & 4.27 & 1.5 & 106.8 \\
\multirow{2}{*}{ Wine } & & 2.0 & 2.11 & 4.3 & 105.5 \\
37263579 & $\mathrm{ND}^{\mathrm{a}}$ & 3.0 & 2.96 & 0.1 & 98.7 \\
& & 4.0 & 3.82 & 1.5 & 95.5 \\
Capsule & \multirow{2}{*}{$\mathrm{ND}^{\mathrm{a}}$} & $29.0^{\mathrm{b}}$ & $28.81^{\mathrm{b}}$ & 5.3 & 99.3 \\
071518 & & $58.0^{\mathrm{b}}$ & $58.31^{\mathrm{b}}$ & 4.6 & 100.5 \\
\hline
\end{tabular}

${ }^{a}$ Not Detected

$\mathrm{b}$ mg/tablelet

${ }^{c} n=5$

The effect of luminol concentration on CL detection was evaluated in the range of $1.0 \times 10^{-6} \sim 1.3 \times 10^{-5} \mathrm{~mol} / \mathrm{L}$. It was found that the $\mathrm{S} / \mathrm{N}$ value increased with luminol concentration increasing and reached maximum at $1.0 \times 10^{-5} \mathrm{~mol} / \mathrm{L}$, whereas the $\mathrm{S} / \mathrm{N}$ values decreased with further luminol concentration increasing. Consequently, $1.0 \times 10^{-5} \mathrm{~mol} / \mathrm{L}$ luminol concentration was selected.

As an oxidant of $\mathrm{CL}$ reaction, $\mathrm{K}_{3} \mathrm{Fe}(\mathrm{CN})_{6}$ affected the $\mathrm{CL}$ signal directly. The effect of $\mathrm{K}_{3} \mathrm{Fe}(\mathrm{CN})_{6}$ concentration on $\mathrm{CL}$ detection was assessed in the range of $1.0 \times 10^{-6} \sim 3.0 \times$ $10^{-5} \mathrm{~mol} / \mathrm{L}$. It was found that the $\mathrm{S} / \mathrm{N}$ value increased with $\mathrm{K}_{3} \mathrm{Fe}(\mathrm{CN})_{6}$ concentration increasing in the range of $1.0 \times$ $10^{-6} \sim 1.0 \times 10^{-5} \mathrm{~mol} / \mathrm{L}$. Higher $\mathrm{K}_{3} \mathrm{Fe}(\mathrm{CN})_{6}$ concentration resulted in a decrease of $\mathrm{S} / \mathrm{N}$ value. Based on above results, $1.0 \times 10^{-5} \mathrm{~mol} / \mathrm{L} \mathrm{K}_{3} \mathrm{Fe}(\mathrm{CN})_{6}$ was selected.

3.6. Analytical Characteristics. A series of standard solutions $\left(1.0 \times 10^{-7} \sim 3.0 \times 10^{-4} \mathrm{~mol} / \mathrm{L}\right)$ was used to determine the analytical figures of merit under the optimum conditions. Experiments showed that $\Delta I$ to vardenafil concentration (C) was linear in the range of $8.0 \times 10^{-7} \sim 1.0 \times 10^{-4}$ $\mathrm{mol} / \mathrm{L}$ with the regression equation of $\Delta I=3.17 C+9.91(C$ : $\left.10^{-6} \mathrm{~mol} / \mathrm{L}, n=5, r=0.9980\right)$ and the detection limit was $5 \times 10^{-7} \mathrm{~mol} / \mathrm{L}(3 \sigma)$. The reproducibility was investigated by injecting $2.0 \times 10^{-5} \mathrm{~mol} / \mathrm{L}$ vardenafil standard for 11 times, which was demonstrated by the RSD. The result indicated that the RSD was 3.6\%. Intraday and inter-day precisions of the described method were examined using the oral liquid sample spiked with $2.0 \times 10^{-5} \mathrm{~mol} / \mathrm{L}$ standard. The intraday precision, defined as the RSD of 5 times determinations to the same sample within one day, five injections one time, was 
Oral liquid

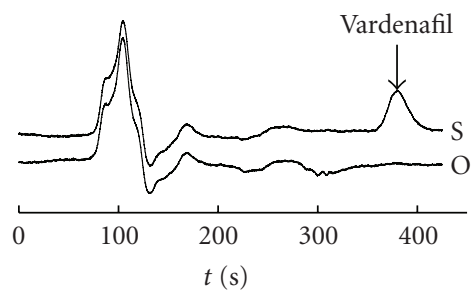

(a)
Capsule

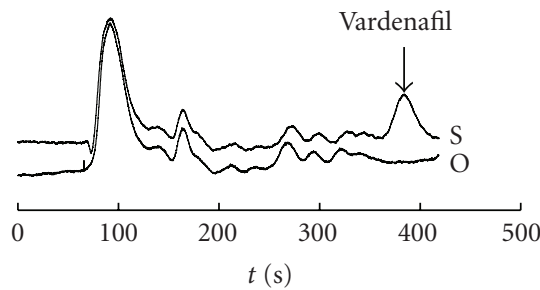

(b)
Wine

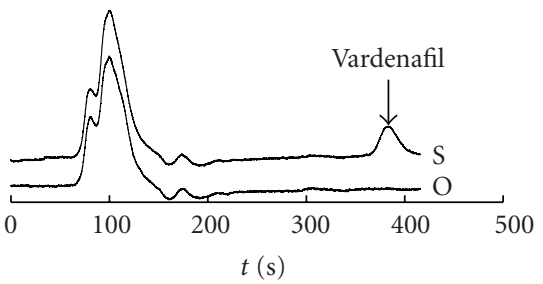

(c)

FIGURE 4: Original $(\mathrm{O})$ and $2.0 \times 10^{-5} \mathrm{~mol} / \mathrm{L}$ vardenafil standard spiked (S) oral liquid, wine, and capsule chromatograms under the optimum conditions.

less than 3.5\%. The inter-day precision, defined as the RSD of five days determinations to the same sample, 5 injections one day, was less than $2.3 \%$. It was concluded that the described HPLC-CL method presented relatively good precision.

3.7. Application. Following the procedures detailed in the experimental section, the proposed HPLC-CL method was applied to determine vardenafil in oral liquid, wine, and capsule samples. The original and vardenafil standard spiked chromatograms of oral liquid, wine, and capsule were shown in Figure 4. It could be seen from Figure 4 that vardenafil was not detected in all three samples and there was no interfering from the endogenous substances at the $t_{R}$ of vardenafil. It was noticed that the $t_{R}$ of vardenafil was $6.4 \mathrm{~min}$, which was much shorter than the $t_{R}$ reported in relative literatures $[1,4,8,9,11,19]$. This shorter $t_{R}$ also implied the time and mobile phase saving.

To evaluate the applicability of the proposed HPLC-CL method for the determination of vardenafil in oral liquid, wine, and capsule, recovery experiments were performed. These experiments were conducted by spiking 3 levels of vardenafil content into oral liquid and wine and adding identical levels of vardenafil content into capsule as shown in Table 3. The recovery percentages were estimated by comparing the concentrations detected from spiked samples with the nominal concentrations added. From experimental results summarized in Table 3 , it was concluded that the proposed method afforded good precision and accuracy when applied to oral liquid, wine, and capsule samples.

\section{Conclusions}

We had carried out the automated HPLC-CL method on vardenafil determination in oral liquid, wine, and capsule samples. Based on the obtained experimental results, the following conclusions could be drawn. A new mobile phase that is composed of $25 \%$ ethanol and $75 \%$ aqueous was found to be nontoxic, environment friendly, and compatible with the alkaline luminol- $\mathrm{K}_{3} \mathrm{Fe}(\mathrm{CN})_{6} \mathrm{CL}$ detection. The short $t_{R}$ contributed high analytical throughput and reagents saving. Relatively good accuracy, precision were obtained as anticipated. The detection limit was acceptable and the linear calibration range was wide. Furthermore, the CL detector was cheap, simple and no sophisticated technique required. In a word, our proposed method might be adopted as an alternative method for vardenafil determination of in dietary supplement.

\section{References}

[1] X. Zhu, S. Xiao, B. O. Chen et al., "Simultaneous determination of sildenafil, vardenafil and tadalafil as forbidden components in natural dietary supplements for male sexual potency by high-performance liquid chromatographyelectrospray ionization mass spectrometry," Journal of Chromatography A, vol. 1066, no. 1-2, pp. 89-95, 2005.

[2] C. L. Cheng, G. J. Kang, and C. H. Chou, "Development and validation of a high-performance liquid chromatographic method using fluorescence detection for the determination of vardenafil in small volumes of rat plasma and bile," Journal of Chromatography A, vol. 1154, no. 1-2, pp. 222-229, 2007.

[3] B. Uslu, B. Dogan, S. A. Özkan, and H. Y. Aboul-Enein, "Electrochemical behavior of vardenafil on glassy carbon electrode: determination in tablets and human serum," Analytica Chimica Acta, vol. 552, no. 1-2, pp. 127-134, 2005.

[4] S. R. Gratz, C. L. Flurer, and K. A. Wolnik, "Analysis of undeclared synthetic phosphodiesterase-5 inhibitors in dietary supplements and herbal matrices by LC-ESI-MS and LC-UV," Journal of Pharmaceutical and Biomedical Analysis, vol. 36, no. 3, pp. 525-533, 2004.

[5] P. Rajagopalan, A. Mazzu, C. Xia, R. Dawkins, and P. Sundaresan, "Effect of high-fat breakfast and moderate-fat evening meal on the pharmacokinetics of vardenafil, an oral phosphodiesterase-5 inhibitor for the treatment of erectile dysfunction," Journal of Clinical Pharmacology, vol. 43, no. 3, pp. 260-267, 2003.

[6] G. Jackson, J. Betteridge, J. Dean et al., "A systematic approach to erectile dysfunction in the cardiovascular patient: a consensus statement," International Journal of Clinical Practice, vol. 53, no. 6, pp. 445-451, 1999.

[7] A. D. Seftel, "Phosphodiesterase type 5 inhibitor differentiation based on selectivity, pharmacokinetic, and efficacy profiles," Clinical Cardiology, vol. 27, no. 4, pp. I14-I19, 2004.

[8] J. C. Reepmeyer and J. T. Woodruff, "Use of liquid chromatography-mass spectrometry and a hydrolytic technique for the detection and structure elucidation of a novel 
synthetic vardenafil designer drug added illegally to a "natural" herbal dietary supplement," Journal of Chromatography A, vol. 1125, no. 1, pp. 67-75, 2006.

[9] P. Zou, S. S. Y. Oh, P. Hou, M. Y. Low, and H. L. Koh, "Simultaneous determination of synthetic phosphodiesterase5 inhibitors found in a dietary supplement and pre-mixed bulk powders for dietary supplements using high-performance liquid chromatography with diode array detection and liquid chromatography-electrospray ionization tandem mass spectrometry," Journal of Chromatography A, vol. 1104, no. 1-2, pp. 113-122, 2006.

[10] M. Abdel-Hamid, "Determination of sildenafil, tadalafil, and vardenafil in tablets and adulterated herbal products by ESI-MS-MS," Journal of Liquid Chromatography and Related Technologies, vol. 29, no. 4, pp. 591-603, 2006.

[11] S. R. Gratz, B. M. Gamble, and R. A. Flurer, "Accurate mass measurement using Fourier transform ion cyclotron resonance mass spectrometry for structure elucidation of designer drug analogs of tadalafil, vardenafil and sildenafil in herbal and pharmaceutical matrices," Rapid Communications in Mass Spectrometry, vol. 20, no. 15, pp. 2317-2327, 2006.

[12] L. Gámiz-Gracia, A. M. García-Campaña, J. F. HuertasPérez, and F. J. Lara, "Chemiluminescence detection in liquid chromatography: applications to clinical, pharmaceutical, environmental and food analysis-A review," Analytica Chimica Acta, vol. 640, no. 1-2, pp. 7-28, 2009.

[13] K. Imai, "Chemiluminescence detection system for highperformance liquid chromatography," in Methods in Enzymology, M. A. DeLuca and W. D. McElroy, Eds., vol. 133 Part B, pp. 435-449, Academic Press, New York, NY, USA, 1986.

[14] T. Slezak, P. S. Francis, N. Anastos, and N. W. Barnett, "Determination of synephrine in weight-loss products using high performance liquid chromatography with acidic potassium permanganate chemiluminescence detection," Analytica Chimica Acta, vol. 593, no. 1, pp. 98-102, 2007.

[15] YI. Lv, S. Zhang, G. Liu, M. Huang, and X. Zhang, "Development of a detector for liquid chromatography based on aerosol chemiluminescence on porous alumina," Analytical Chemistry, vol. 77, no. 5, pp. 1518-1525, 2005.

[16] N. Niina, H. Kodamatani, K. Uozumi, Y. Kokufu, K. Saito, and S. Yamazaki, "Simultaneous detection of monoethanolamine, diethanolamine, and triethanolamine by HPLC with a chemiluminescence reaction and online derivatization to tertiary amine," Analytical Sciences, vol. 21, no. 5, pp. 497-500, 2005.

[17] J. W. Costin, S. W. Lewis, S. D. Purcell, L. R. Waddell, P. S. Francis, and N. W. Barnett, "Rapid determination of Papaver somniferum alkaloids in process streams using monolithic column high-performance liquid chromatography with chemiluminescence detection," Analytica Chimica Acta, vol. 597, no. 1, pp. 19-23, 2007.

[18] C. Huang, G. Zhou, H. Peng, and Z. Gao, "Simultaneous determination of N,N-dimethylaniline and phenol in wastewater by high-performance liquid chromatography with chemiluminescence detection," Analytical Sciences, vol. 21, no. 5, pp. 565-567, 2005.

[19] Z. Zhang, S. Kang, M. Xu, M. Ma, BO. Chen, and S. Yao, "Determination of sildenafil and vardenafil in human plasma by high performance liquid chromatography coupled with liquid-liquid-liquid microextraction," Chinese Journal of Chromatography, vol. 23, no. 4, pp. 358-361, 2005.

[20] R. J. Motyka, P. Gerhards, and S. Sadjadi, "Determination of Levitra (Vardenafil $\mathrm{HCl}$ ) in Plasma Using Polymer-Based SPE and LC-MS-MS," LC-GC North America, vol. 22, no. 4, pp. 57$61,2004$. 


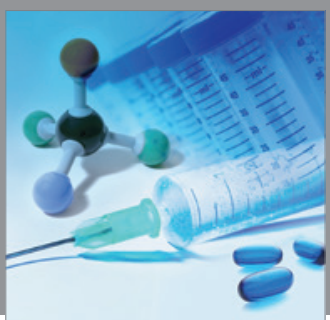

International Journal of

Medicinal Chemistry

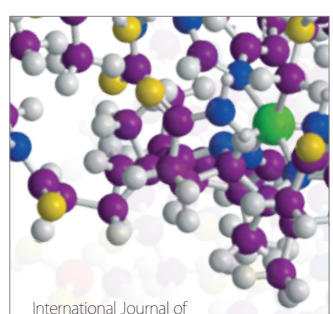

Carbohydrate Chemistry

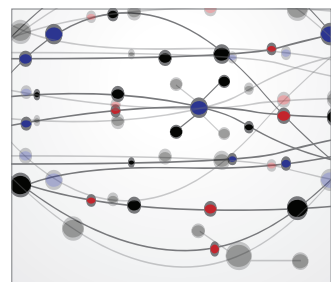

The Scientific World Journal
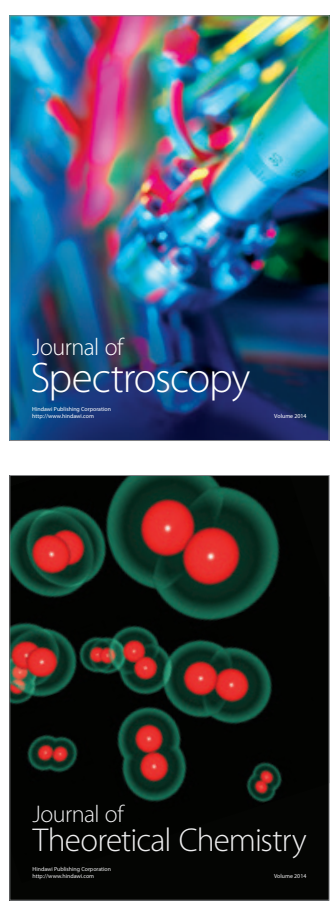
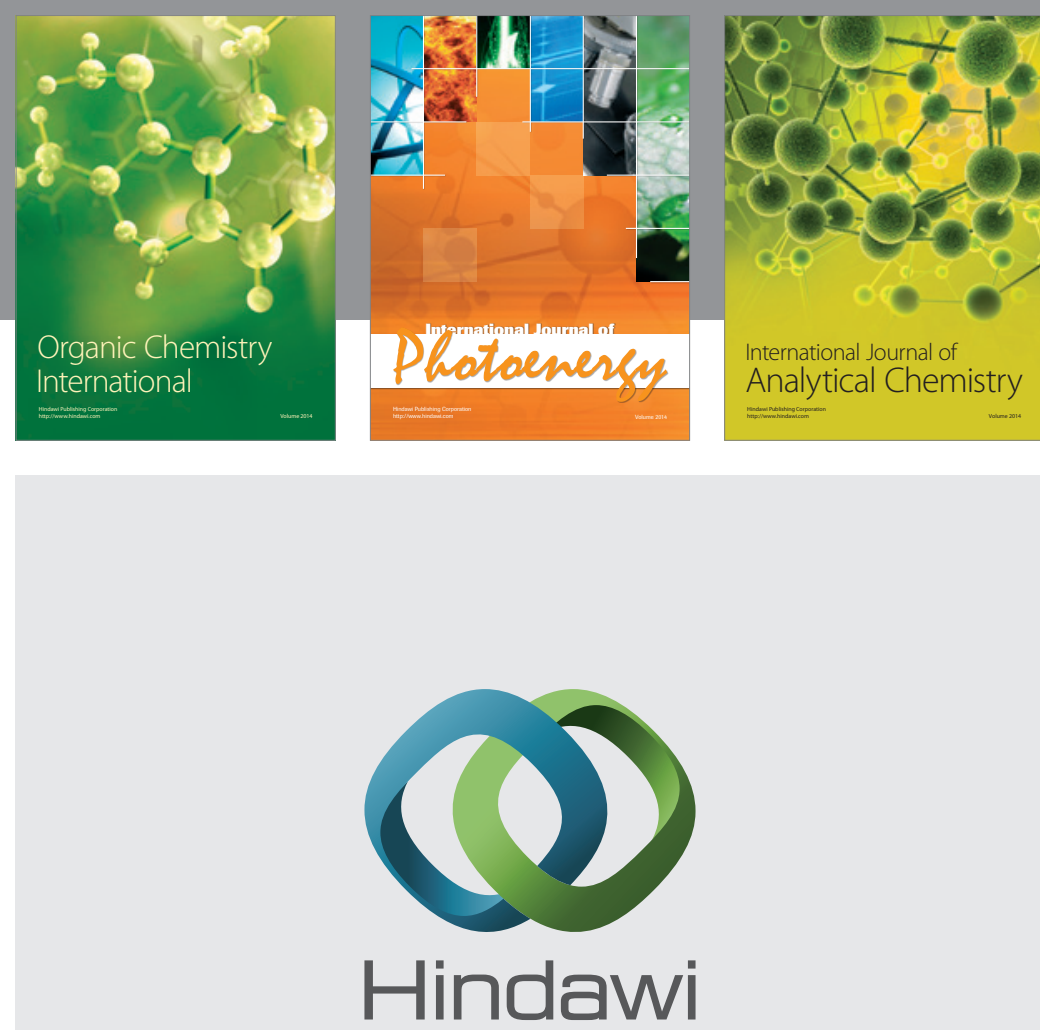

Submit your manuscripts at

http://www.hindawi.com
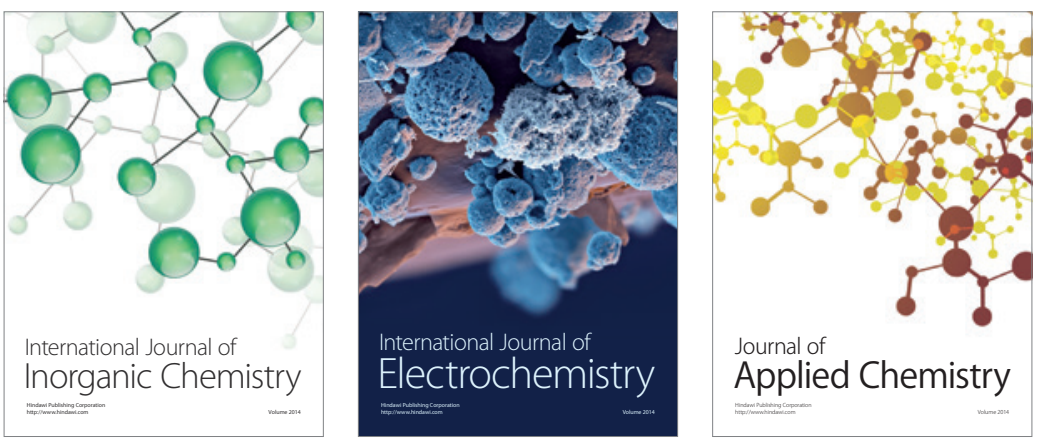

Journal of

Applied Chemistry
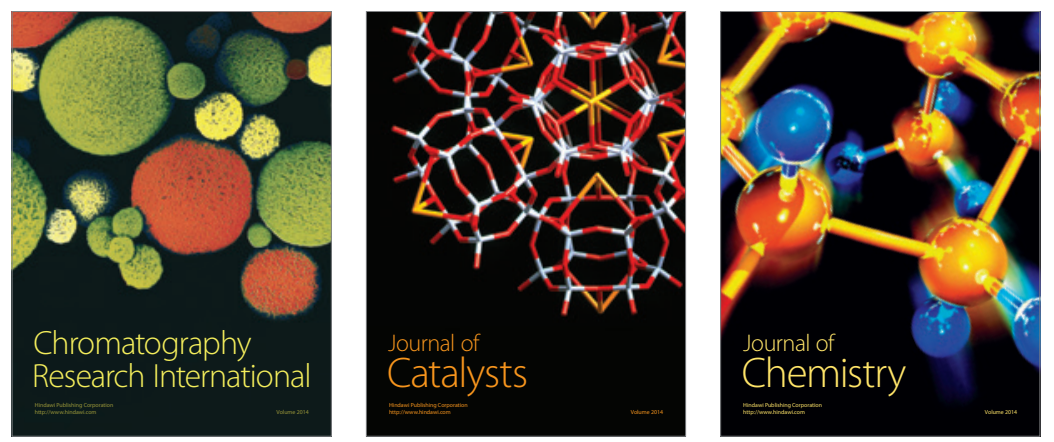
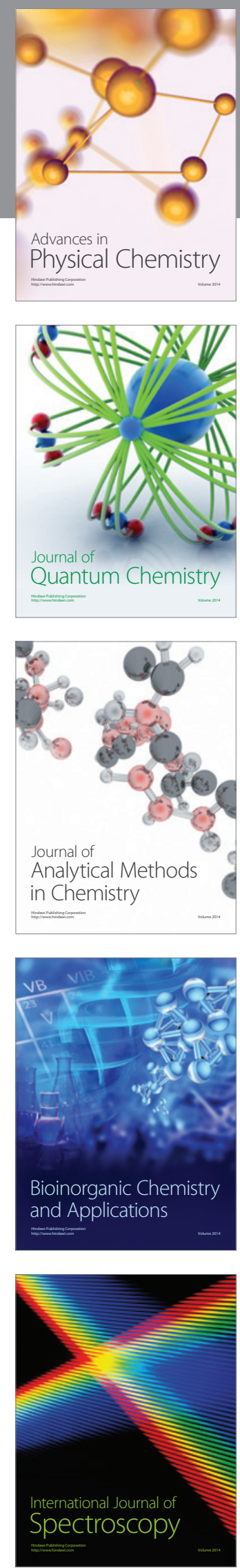